\title{
IMPORTÂNCIA DA MICROCIRURGIA EXPERIMENTAL PARA TRANSPLANTES DE ÓRGÃOS ${ }^{1}$
}

\author{
Paulo Ney Aguiar Martins ${ }^{2}$
}

\begin{abstract}
Martins PNA. A importância da microcirurgia experimental para transplante de órgãos. Acta Cir Bras [serial online] 2003 Jan-Fev;18(1). Disponível em URL: http://www.scielo.br/acb.

RESUMO - A microcirurgia experimental é uma área relativamente nova e seu desenvolvimento foi um marco importante para o desenvolvimento da pesquisa imunológica e de técnicas cirúrgicas de transplante, pois permitiu a utilização de modelos animais de pequeno porte; mais apropriados para pesquisa, e com menor custo. A microcirurgia exige bastante habilidade técnica e treinamento continuo. Além disso contribui para formação do cirurgião de transplantes na medida que promove o desenvolvimento de habilidade manual, interesse científico e cooperação interdisciplinar. Esse artigo relata alguns aspectos históricos, a importância e as vantagens e limitações da microcirurgia experimental.
\end{abstract}

DESCRITORES - Microcirurgia. Modelos cirúrgicos. Transplante.

Microcirurgia experimental é o conjunto de técnicas para realizar atos operatórios em pequenos animais, como roedores, utilizando microscópio e instrumentos especiais que permitem confeccionar anastomoses de estruturas com diâmetros inferiores a $0,3 \mathrm{~mm}$. Os primeiros experimentos com microcirurgia para anastomose vascular foram realizados por Dr. Sun Lee na Universidade de Pittsburg em 1958, ao executar anastomose porto-cava término-lateral em ratos ${ }^{1}$. Até essa época, transplantes de pele não vascularizados eram o único modelo utilizado por pesquisadores para estudar a imunologia de transplante ${ }^{2}$. $\mathrm{Na}$ década de 70, a maioria das técnicas de transplantes em ratos já tinham sido estabelecidas, tornando factível a realização de transplante de rim, coração, coração-pulmão, figado, pâncreas, intestino, estômago, timo, testículo e enxerto vascularizado de pele $3,4,5,6,7,8,9,10,11,12,13$. Criou-se assim um elo entre pesquisa imunológica e cirurgia experimental. Na década de 90 , foram desenvolvidas técnicas para cirurgia em camundongos, exigindo mais domínio técnico em virtude do menor diâmetro dos vasos ${ }^{14,15}$.

A microcirurgia abriu novas fronteiras para pesquisa sobre fisiopatologia e imunologia de transplantes.
A aplicação de técnicas de microcirurgia experimental tem gradualmente aumentado, o que é refletido pelo aumento do número de publicações e congressos nessa área.

O transplante experimental utilizando ratos e camundongos se tornou o modelo ideal para estudos immunológicos. Entre as vantagens do modelo ratocamundongo estão:

* Menor custo. O preço de roedores é bastante inferior ao de animais de grande porte. Além disso, devido ao menor tamanho, necessita-se de menos espaco; menor custo e facilidade de manutenção; menos material anestésico, cirúrgico e menos droga immunossupressiva. Permite-se, dessa forma, que grande quantidade de animais seja utilizada, o que contribui para que os resultados tenham maior valor estatístico.

* Maior praticidade. A manipulação desses animais é mais fácil. É necessário apenas um operador e as cirurgias são mais rápidas e não necessitam de material esterilizado.

1. Departamento de Cirurgia de Transplante. Charité-Virchowklinikum (Humboldt Universität zu Berlin).

2. Fellow de Cirurgia de Transplante. Bolsista da CAPES. 
* Maior disponibilidade de tecnologia. Reagentes; anticorpos monoclonais; e linhagens congênicas, transgênicas e "knock-out" de ratos e camundongos são mais disponíveis; facilitando o estudo da imunologia do transplante.

* Ciclo de vida mais curto. Pelo fato de apresentarem expectativa de vida menor, em torno de 1-2 anos, facilita o estudo de rejeição crônica e influência da idade em mecanismos imunológicos.

* Menor sensibilização da população em relação a esses animais. A crescente pressão pública e de órgãos de proteção animal, em relação ao uso de animais de grande porte para pesquisa, limitou a utilização dos mesmos.

* Desenvolvimento de habilidade técnica. Microcirurgia exige alto grau de qualidade técnica devido ao diminuto tamanho e sensibilidade das estruturas, oferecendo possibilidade de treinamento principalmente para as áreas de cirurgia vascular, de mão, transplantes, plástica, e neurocirurgia.

As limitações da utilização do modelo ratocamundongo são associadas a grande diferença genética entre roedores e o ser humano ${ }^{16}$. Fatores limitantes importantes são a facilidade de indução de tolerância e ausência de reação de rejeição hiperaguda ${ }^{17,18}$. A aceitação do transplante ocorre frequentemente em ratos, e principalmente em camundongos; após curto período de imunossupressão, ou mesmo espontaneamente. Isso torna necessário a complementação de experimentos em primatas antes da aplicação do conhecimento em seres humanos. No futuro a recombinação do sistema immune do rato com células imunes humanas através de técnicas de engenharia genética permitirá a criação de um modelo mais semelhante ao humano para estudo da imunologia do transplante ${ }^{19}$.

$\mathrm{O}$ equipamento básico para microcirurgia assemelha-se com o usado em oftalmologia e neurocirurgia, e consiste em: microscópio com aumento de até 40 vezes, pincas tipo Wright, porta-agulha e tesoura microcirúrgicos, mini Satinsky, mini bulldogs, clamps vasculares para neurocirurgia, aplicador de clamp, fios de sutura monofilamentar (prolene ou nylon 7.0-11.0 com agulha atraumática de $6 \mathrm{~mm}$ ou nylon 14 microns com agulha de $3 \mathrm{~mm}$ ), catéteres $22 \mathrm{G}$ e hastes flexíveis de algodão.

A microcirurgia utiliza uma nova dimensão óptica e exige alto grau de qualidade técnica, paciência, concentração, tolerância a frustração e treinamento contínuo. A qualidade técnica, importante em qualquer cirurgia, se torna mais importante ainda quando se trata de realização de delicadas anastomoses vasculares. A habilidade adquirida durante o treinamento em microcirurgia torna o cirurgião ou residentes de cirurgia de transplantes de órgão mais familiarizados com técnicas de sutura e reconstrução vascular, que auxilia na prática clínica. Muitos centros de transplantes já incorporam treinamento em microcirugia em seu programa de residência e a tendência futura é que seja prática comum durante treinamento em cirurgia de transplante. A coordenação da percepção óptica e habilidade manual é aprendida mais facilmente por pessoas mais jovens ${ }^{20}$. Durante esse período o residente desenvolve além de habilidade manual, interesse científico e cooperação com outros grupos de pesquisas, como patologistas, imunologistas e clínicos . O futuro exige do cirurgião de transplantes além de conhecimento; qualidade técnica crescente, interesse científico e cooperação interdisciplinar.

\section{REFERÊNCIAS}

1. Lee SH, Fisher B. Portacaval shunt in the rat. Surgery 1961; 50:668-72.

2. Billingham RE, Krohn P, Medawar PB. Effect of cortisone on the survival of skin homografts in rabbits. Br Med J 1951; 1.1157-63.

3. Lee S. An improved technique of renal transplantation in the rat. Surgery 1967;61: 771-3.

4. Lee S. Historical significance on rat organ transplantation. Microsurgery $1990 ; 11: 115-21$.

5. Lee $\mathrm{S}$. Contribution of microsurgery in transplantation progress. Microsurgery 1990; 11:289.

6. Lee S. History and development of experimental microsurgery. In: Timmermann W, Gassel HJ, Ulrichs K, Zhong R, Thiede A. Organtransplantation in rats and mice. 1ed. Springer; 1998. p $3-15$.

7. Abbot CP, Lindsey ES, Creech O Jr, DeWitt CW. A technique for heart transplantation in the rat. Arch Surg 1964;89:645-52.

8. Lee S, Willoughby WF, Smallwood CJ, Dawson A, Orloff MJ. Heterotopic heart and lung transplantation in the rat. Am J Pathol 1970;59: 279-97.

9. Lee S, Tung KSK, Orloff MJ: Testicular transplantation in the rat. Transplant Proc 1971;3: 586-90.

10. Lee S, Edgington TS: Liver transplantation in the rat. Surg Forum 1996;7:220-2.

11. Reemtsdma K, Giraldo N, Depp DA, Eichwald EJ. Islet cell transplantation. Ann Surg 1968;168: 436-46.

12. Lee S, Edgington TS, Smallwood CJ, Thompson AG, Chandler JG. Rosen H, Orloff MJ. Secretory function and relative resistance of the gastric mucosa of the rat to allogenic rejection. Transplantation 1972;14: 641-8.

13. Monchick GK, Russel PS. Transplantation of small bowel in the rat: technical and immunological considerations. Surgery 1971;70:693-702.

14. Quin S, Fung J, Demetris A. Orthotopic liver transplantation in the mouse. Transplantation 1991, 52:562-4.

15. Zhong R. Organ transplantation in mice: current status and future prospects. Microsurgery 1999; 19:52-5. 
Importância da microcirurgia experimental para transplantes de órgãos

16. Günter E, Walter L. The major histocompatibility complex of the rat. Immunogenetics 2001.

17. Quin S, Demeteris A, Murase N, Rao A, Fung J, Starzl T. Murine liver allograft transplantation: tolerance and donor cells chimerism. Hepatology 1994; 19: 916-24

18. Baldwin WM, Pruitt SK, Brauer RB, Daha MR, Sanfillippo. Complement in organ transplantation contributions to inflammation, injury, and rejection. Transplantation 1995; 59:797-808
19. Alegre ML, Peterson LJ, Jeyarajah DR, Weiser M, Bluestone JA, Thistlethwaite JR. Severe combined immunodeficient mice engrafted with humans splenocytes have functional human t cells and reject human allografts. J Immunol 1994; 153: 2738-49.

20. Thiede A, Timmermann W., Gassel HJ. Experimental microsurgery as an educational concept and scientific basis for research group: principles of technical development of animal models in transplantation research. In: Timmermann W. Organ transplantation in rats and mice.1ed. Springer;1998. p 17-24.

Martins PNA. The importance of experimental microsurgery for transplantation. Acta Cir Bras [serial online] 2003 Jan-Feb;18(1). Available from URL: http://www.scielo.br/acb.

ABSTRACT - Microsurgery was an hallmark for the transplantation immunological research and development of surgical techniques because it allowed the use of rodent models, which are more appropriate for research and more cost-effective. Microsurgery demands high technical skills and continuous training, and helps transplantation surgeons; since it promotes the development of surgical skills, scientific interest and interdisciplinary cooperation. This article reviews some aspects of the history, advantages and limitations of experimental microsurgery and its importance for the development of transplantation surgery.

KEY WORDS - Microsurgery. Casts, surgical. Transplantation.

Conflito de interesse: nenhum

Fonte de financiamento: CAPES

Correspondência:

Dr. Paulo Ney A. Martins

Virchow Klinikum

Forschungshaus R. 2.104 (AG Tullius)

Augustenburger Platz 1, 13353, Berlin, Germany

Tel:(00) $49304502-1823$

drpauloney@yahoo.com

Data do recebimento: 25/09/2002

Data da revisão: 13/10/2002

Data da aprovação: 05/11/2002 